\title{
Electrical and Structural Properties of Polystyrene/Graphite Composite by Direct Mixing Method
}

\author{
Stella Ezeonu Emmanuel Ogonnaya ${ }^{*} \quad$ Christian Nweze \\ Department of Physics/Industrial Physics, nnamdi Azikiwe University, Awka, Nigeria
}

\begin{abstract}
Melt mixing method was used in the preparation of Polystyrene (PS)/graphite composite with different graphite weight $\%$. The electrical and structural properties of the composite were studied using Keithley two-point probe and GBC EMMA X-ray diffractometer (XRD) respectively. The result showed that the electrical conductivity of the composites was improved as the weight percentage of graphite content increases but the percolation threshold was observed at $0.10 \mathrm{wt} \%$. The conductivity of the composites was also observed to increase at higher temperatures. The structural result showed that the amorphous structure of polystyrene was converted to crystalline as the weight $\%$ of the graphite increases which influences the degree of crystallinity.
\end{abstract}

Keywords: polymer, graphite, composite, percolation threshold, electrical conductivity

DOI: $10.7176 /$ APTA/81-03

Publication date: December $31^{\text {st }} 2019$

\section{Introduction}

Polymers are one of the most successfully exploited classes of material because of their unique properties and are fast replacing inorganic semiconductors in industries ${ }^{1}$. The high cost of inorganic conducting and semiconducting materials have called for research into possible flexible, affordable and also efficient materials for replacing the expensive inorganic material that dominates the electronic industries. Most commercially produced organic polymers are electrically non-conducting and a lot of attempts have been made to enhance its properties using dopants $^{2-5}$. As the dopant content is increased in a polymer matrix, there is a gradual transition from the predominant polymer properties to the properties of the filler. Blending polymers with conductive particles are known to increase its electrical conductivity ${ }^{6-8}$. The transition point at which the conductive particle properties start to be dominant is referred to as the percolation threshold and at this point, the polymer transit from its electrical insulator characteristic to that of semiconductor/conductor. In this study, graphite was chosen as the conductive filler because of its unique properties (It has the properties of metal and non-metal) and is also chemically inert. Polystyrene, one of the most widely used as packaging materials/ plastics are abundant in our environment as litters. It is also chemically inert. Polystyrene/graphite composites have been studied by some researchers using different methods ${ }^{9-11}$. In this research work, the polystyrene/graphite composite was fabricated by direct mixing using industrial extruder and injection moulding machine.

\section{Experimental}

The graphite powder with a particle size of $50 \mu \mathrm{m}$ was supplied by Merck \& Co., USA. The polystyrene (with an average diameter of pellet $\approx 2.35 \mathrm{~mm}$ and length $\approx 2.70 \mathrm{~nm}$ ) was obtained from British Drug House $(\mathrm{BDH}) \mathrm{chemical}$ limited. The acetone, Poly vinyl alcohol, (PVA), were supplied by Sigma - Aldrich, Canada. All these were used without further purification.

\section{Method/Sample Preparation}

The mould was rinsed with acetone to remove any contaminants. The mould was then coated with a mould releasing agent (PVA) to allow easy removal of the samples after formation and allowed to dry. $100 \mathrm{~g}$ weight of polystyrene was measured and poured into the injection moulding machine and then heated up. The polystyrene melted at a temperature of $240^{\circ} \mathrm{C}$ and was casted into the already coated mould which solidifies within 5 mins. This serves as the control sample.

The same weight of polystyrene was poured into the moulding machine which liquidifies at a tempertature of $240^{\circ} \mathrm{C}$ after which $0.01 \%$ ( $0.01 \%$ of the weight of the polysyrene) of graphite was added to it. A uniform composite was achieved by the application of shear force by the injection moulding machine. The mixture was then casted into a Teflon mould coated with a PVA mould releasing agent which took about $5 \mathrm{mins}$ to solidify. The sample was removed and labeled. The same procedure was used for all the different weight percentage of graphite powder $(0.10,0.15,0.20,0.50,1.00$, and 3.00$)$. The dimension of the samples is $100 \mathrm{~mm} \times 100 \mathrm{~mm} \times 3 \mathrm{~mm}$ which is the dimension of the Teflon mould.

\section{The characterization of the samples}

The composite samples were characterized for their electrical and structural properties using two point probe and $\mathrm{X}$-ray diffractometer respectively. The two point probe is used to measure resistivity of near insulator samples 
which are beyond the range of four point probe Electrical conductivity of the polystyrene/graphite composite was carried out at room temperature $\left(27^{\circ} \mathrm{C}\right)$. The samples were also analyzed at different temperatures, $60^{\circ} \mathrm{C}, 80^{\circ} \mathrm{C}$ and $100^{\circ} \mathrm{C}$. These temperatures were achieved by heating the samples in an oven. The oven and the Keithley two point probes were placed very close to each other. The heated samples were immediately transferred to the two point probe to avoid loss of heat.The structural analysis of the samples were performed using X-ray diffractometer, equipped with $\mathrm{CuK} \alpha$ radiation $(\lambda=1.54178 \AA)$, with an acceleration voltage of $25 \mathrm{KV}$ and current of $40 \mu \mathrm{A}$. The diffraction angle $2 \theta$ was scanned from $10^{\circ}$ to $50^{\circ}$ step size of $0.05^{\circ}$, and rate of $2.00^{\circ} / \mathrm{min}$. The percentage crystallinity and crystallite size were calculated using standard equations.

\section{Results and discussion}

The two point probe was used to determine the resistivity of the composites. From the resistivity, the conductivity of the composites was calculated using the relationship between them. The effect of the graphite at different weight percentage is demonstrated in figure 1.

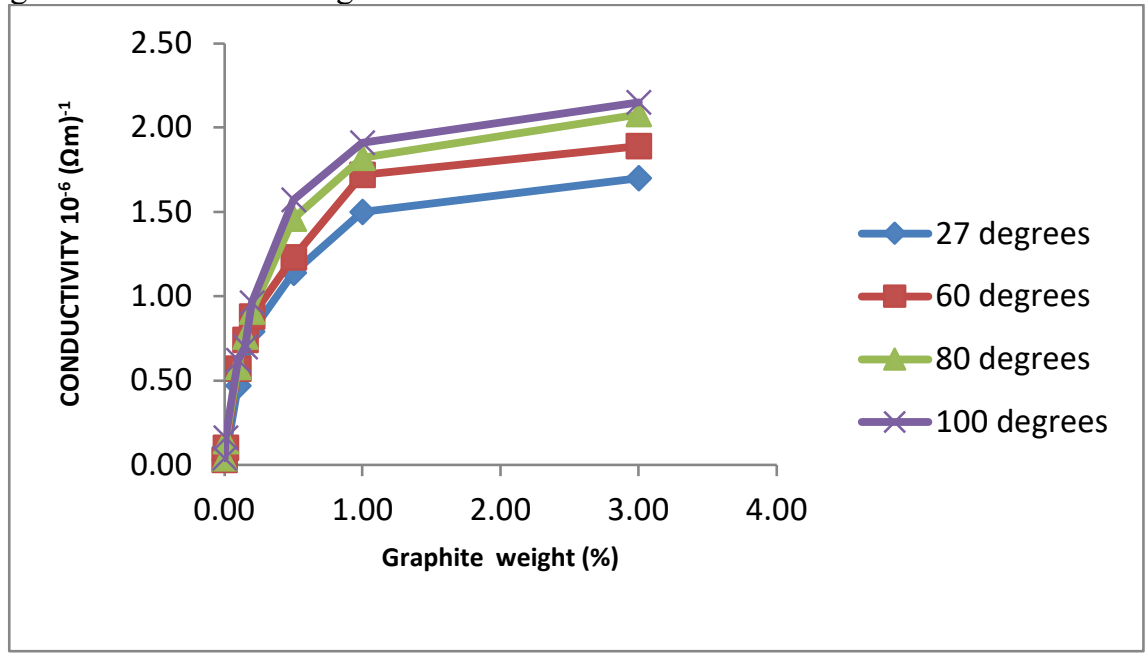

Figure 1: electrical conductivity against graphite $\mathrm{wt} \%$ at different temps

It shows the plot of conductivity of the composite against graphite weight $\%$ at different temperatures. It was observed that at room temperature $\left(27^{\circ} \mathrm{C}\right)$, the conductivity of the control sample is $0.03 \times 10^{-6}(\Omega \mathrm{cm})^{-1}$. A similar value was obtained on addition of $0.01 \%$ graphite weight. At $0.10 \%$, a dramatic increase in conductivity was observed, indicating the triggering of percolation threshold. At percolation threshold, the graphite particles make contact with each other and provide continuous conductive network through the composite structure. The percolation threshold obtained at $0.10 \%$ wt graphite agrees with the work of Stankovich et al 2006.

By further increasing the graphite loading, the electrical conductivity continues to increase as was observed by Guohua et el 2003. An increase in conductivity of the composites as the weight\% dopant increases was further observed at $60^{\circ} \mathrm{C}, 80^{\circ} \mathrm{C}$ and $100^{\circ} \mathrm{C}$ respectively. This significant increase in conductivity as the weight concentration is increased could be attributed to increase in ionic charge carriers and charge mobility ${ }^{12}$. Similar result was reported by kelechi and Eboatu 2014. The X-ray measurement used was to investigate and study the changes of the nature of polystyrene after the addition of graphite of different weight percentage. Figure $2 a$ and $2 b$ show the XRD pattern of pure polystyrene and graphite respectively. The largest specific diffraction at $2 \theta$ between $15^{\circ}-20^{\circ}$ indicates that pure polystyrene is armophous while in figure $2 \mathrm{~b}$, the two prominent peaks at $2 \theta=26.35^{\circ}$ and $43.17^{\circ}$ which corresponds to (002) and (101) planes of reflection shows that graphite is crystalline in nature. From the XRD analysis, the lattice constant is found to be $\mathrm{a}=2.461 \AA$ and $\mathrm{c}=6.708 \AA$. The calculated crystallite size of graphite is $304.06 \AA$. 


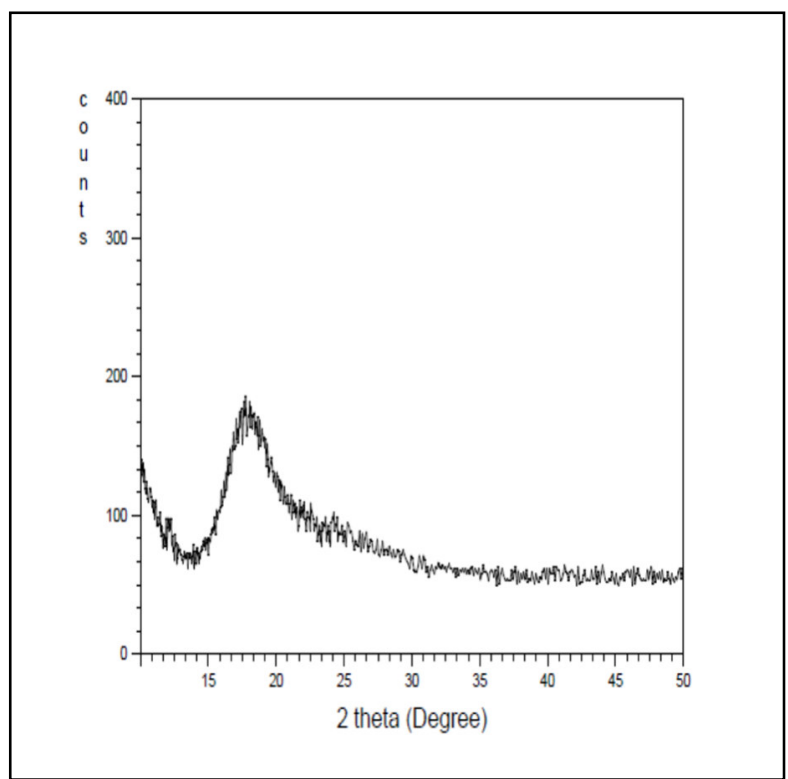

Figure 2a: XRD pattern of polystyrene

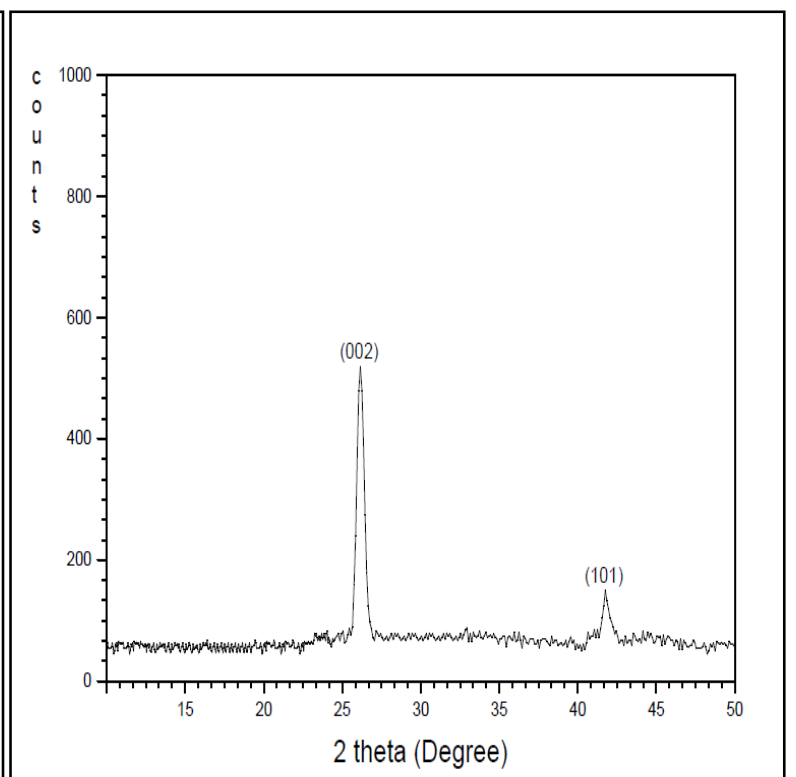

Figure 2b: XRD pattern of graphite

Figure 3 shows the XRD pattern of polystyrene with $0.01,0.10,0.15,0.20,0.50,1.00$ and $3.00 \mathrm{wt}^{\mathrm{O}} \%$ of graphite particles. As the weight $\%$ of the graphite increases, the diffraction angle of the peaks shift slightly and the intensities increases indicating a structural modification. This modification could be observed by the prominent peaks that appeared in the XRD pattern of doped polystyrene, this modification changed the structure of pure polystyrene from armophous to crystalline as evidence in the intensities of the peaks and in the $\mathrm{d}$ spacing (interplanar spacing) as the weight $\%$ of graphite increases from $0.01-3.00 \mathrm{wt} \%$.

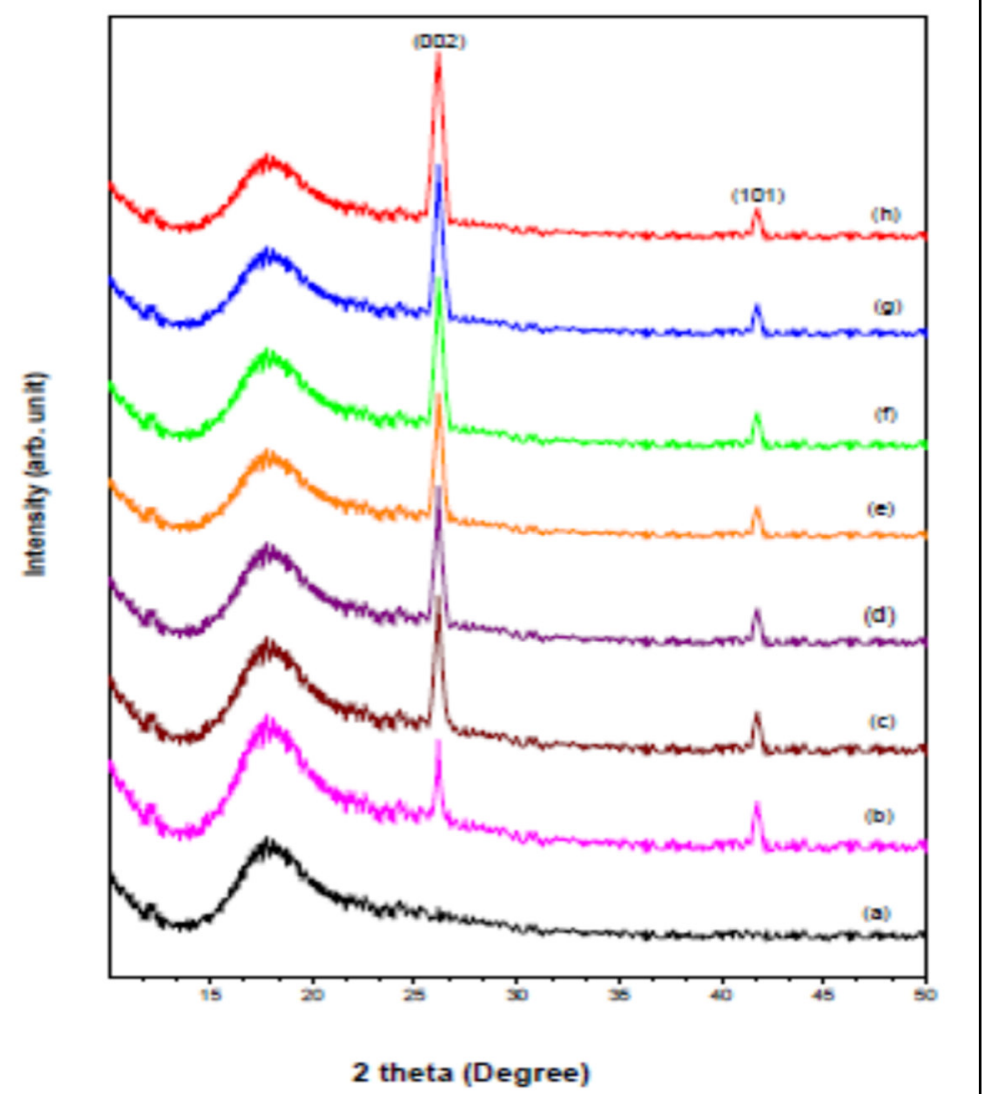

Figure 3: XRD pattern of polystyrene/graphite at different $\mathrm{wt} \%$ $(\mathrm{a}=0 \%, \mathrm{~b}=0.01 \%, \mathrm{c}=0.10 \%, \mathrm{~d}=0.15 \%, \mathrm{e}=0.2 \%, \mathrm{f}=0.5 \%, \mathrm{~g}=1.0 \%, \mathrm{~h}=3.0 \%)$

The crystallite size D is calculated using sherrer's formular;

$$
\mathrm{D}=\frac{\mathrm{K} \lambda}{\beta \cos \theta}
$$


Where, $\mathrm{D}$ is the particle size $(\AA), \mathrm{K}=$ constant (usually $\mathrm{k}=0.89), \lambda=$ wavelength of the incident $\mathrm{X}$-ray beam, $\beta=$ full width at half maximum of the X-ray diffraction peaks (rad) and $\theta=$ Bragg angle of X-ray diffraction peak. The percentage crystallinity $\mathrm{X}_{\mathrm{c}}$ is calculated by dividing the total area of crystalline peak by the total area under the diffraction curve (crystalline plus amorphous)

$$
\mathrm{X}_{\mathrm{c}}=\left[\frac{\mathrm{I}_{\text {crystalline }}}{\mathrm{I}_{\text {crystalline }}+\mathrm{I}_{\text {amorphous }}}\right] \times 100
$$

It is found that the crystallite size decreased with increase in doping content while the degree of crystallization increased with the dopant weight $\%$ as shown in Table 1.

Table 1 crystallite size and the degree crystallization of polystyrene/graphite

\begin{tabular}{|c|c|c|}
\hline PS/Graphite (weight\%) & Crystallite size $(\AA)$ & Degree of crystallization \\
\hline $\mathbf{0 . 0 1}$ & 335.71 & 11.30 \\
\hline 0.10 & 319.09 & 16.76 \\
\hline 0.15 & 287.75 & 18.27 \\
\hline 0.20 & 282.71 & 19.71 \\
\hline 0.50 & 264.17 & 20.09 \\
\hline 1.00 & 259.91 & 21.11 \\
\hline 3.00 & 255.78 & 24.79 \\
\hline
\end{tabular}

The presence of graphite significantly influences the degree of crystallization as shown in figure 4 . The degree of crystallization increases with the graphite weight $\%$ but with a decrease in crystallite size.

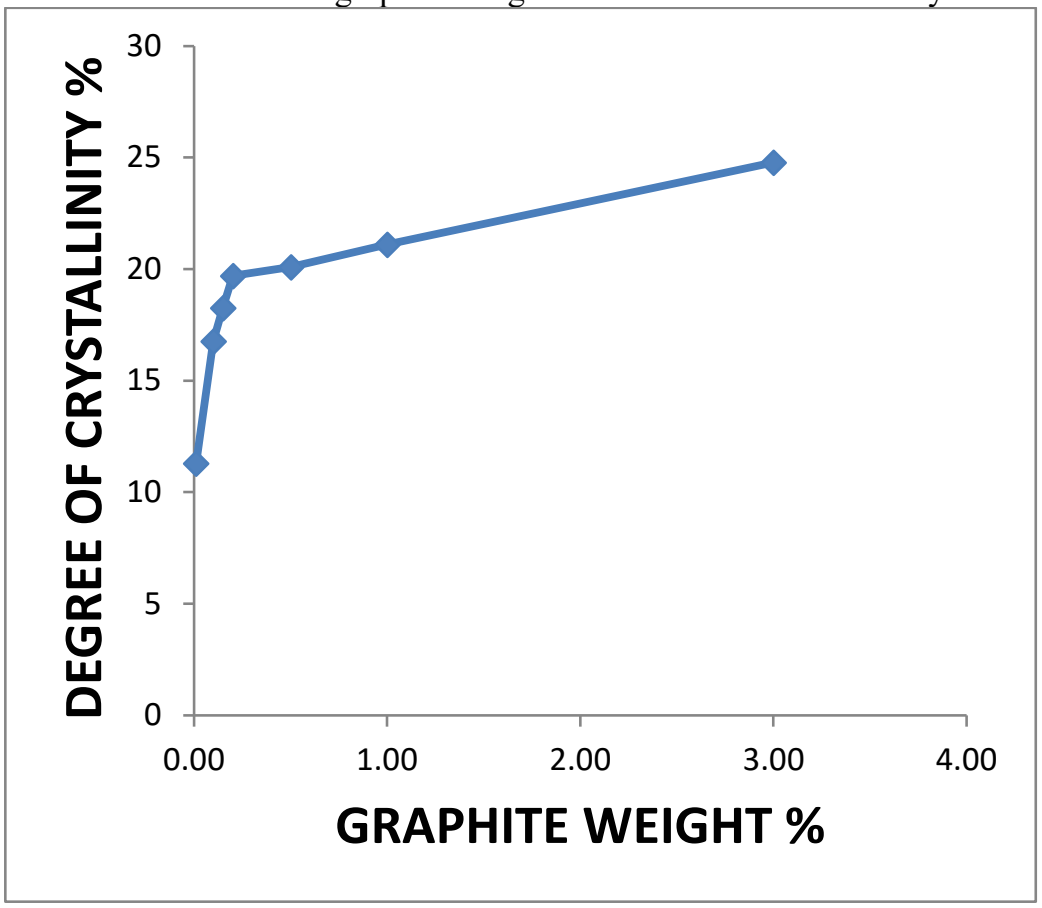

Figure 4: degree of crystallinity against PS/graphite composite with different graphite wt\%

\section{Conclusions}

The polystyrene/graphite composite with different graphite weight $\%$ was successfully prepared by melt mixing method. The results showed that the electrical conductivity of the composite increased as the graphite weight $\%$ increased and percolation threshold was observed at a very low loading of graphite at $0.10 \%$. The temperature was also found to have a considerable effect on the composite and help in enhancing its electrical conductivity. The composite display a crystalline nature as against the armophous nature of pure polystyrene. The graphite content significantly influences the degree of crystallization and the crystallite size of the composite sample. Hence the enhancement of properties of the composite offer the promise of a new generation of materials with several possibilities of applications such as in electrical devices and sensors.

\section{References}

Alghunaim N .S (2018). Structural, thermal, dielectric and AC impedance properties of SiC nanoparticles doped PVK/PVC. Results in Physics, 9: 1136-1140

Cao J.P, Zhao J, Zhao X, Hu G.H and Dang Z.M (2013). Preparation and characterization of surface modified silicon carbide/polystyrene. J. Appl Polym Sci, 130: 638-644 
Chen G.H, Wu C.L, Weng W.G, Wu D.J and Yan W.L ( 2003). Preparation of polystyrene/graphite nanosheet composites. Polymer 44(6) : 1781-1784

Chen G.H, Wu D.J , Weng W.G, He B and Yan W.L ( 2001). Preparation of polystyrene-graphite conducting nanocomposites via intercalation polymerization. Polymer International 50 (9): 980-985.

Feng J, Athanassiou A Bonaccorso F and Fragouli D (2018). Enhanced electrical conductivity of poly(methyl methacrylate) filled with graphene and in situ synthesized gold nanoparticles. NanoFuture 2 (2) : 1-8

Hezma A.M, Elashmawi I .S, Abdelrazek E .M, Rajeh A, Kamal M (2017). Enhancement of the thermal and mechanical properties of polyurethane/polyvinyl chloride blend by loading single walled CNT. Progress in Natural Science Materials International, 23 (3): 338-343.

Jelmy E .J , Ramakrishnan S, Rangarajan M and Kothurkar N .K (2013). Effect of different carbon fillers and dopant acids on electrical properties of polyaniline nanocomposite. Bull. Mater. Sci, 36 (1): 37-44

Jin, J., Lin, Y., Song, M., Gui, C., \& Leesirisan, S. (2013). Enhancing the electrical conductivity of polymer composites. European Polymer Journal, 49(5), 1066 - 1072

Kelechi U. and Eboatu A. N. (2014). Comparative studies of the effects of doping on the electrical and thermal conductivities of polystyrene, The Pacific Journal of Science and Technology, 15(1): 200-205

Ma P, Liu M, Zhang H, Wang S, Wang R, Wang K, Wong Y, Tang B, Hong S, Paik K and Kim J (2009). Enhanced Electrical Conductivity of Nanocomposites Containing Hybrid Fillers of Carbon Nanotubes and Carbon Black. ACS Appl. Mater. Interfaces, 1 (5): 1090-1096

Wang W and Pan C (2004). Preparation and characterization of polystyrene/graphite composite prepared by cationic grafting polymerization. Polymer 45 (12) : 3987- 3995

Wiley J (1976). In Raya A.A and Majeed A.H(2013). Effect of cobalt chloride $\left(\mathrm{CoCl}_{2}\right)$ on the electrical and optical properties of (PVA-PVP-CoCl 2 ) films. Advances in Physics Theories and Applications 18: 47-53 